\title{
Recruiting Managers with the Lure of CPD
}

\author{
Carl Evans (Corresponding author) \\ University of Worcester Business School, \\ Henwick Road, Worcester, WR2 6AJ England. \\ Tel: 01905855358 E-mail: c.evans@worc.ac.uk \\ Gbolahan Gbadamosi \\ University of Worcester Business School, \\ Henwick Road, Worcester, WR2 6AJ England. \\ Tel: 01905855358 E-mail: g.gbadamosi@worc.ac.uk
}

\begin{abstract}
Increasingly managerial posts are being advertised with CPD (Continuing Professional Development) as a stated benefit alongside the usual job benefits of bonus, car, life assurance etc. Yet CPD as a job perk, rather than an integral element of the person specification, not only challenges the underlying premise of CPD; it is morally inappropriate.

While CPD has become a universal term, whose use covers a wide range of professions (e.g. law, accounting, architecture, teaching, engineering, town planning, and medicine), in this paper, we specifically focus on CPD for managers, particularly examining why managers should be concerned with CPD and discussing the implications for managers of CPD being specified as a job benefit.
\end{abstract}

Keywords: Managers, CPD, Recruitment, Job Advertisements,

\section{Introduction}

Increasingly managerial posts are being advertised with CPD (Continuing Professional Development) as a stated benefit alongside the usual job benefits of bonus, car, life assurance etc. Yet CPD as a job perk, rather than an integral element of the person specification, not only challenges the underlying premise of CPD; it is morally inappropriate.

\section{Discussion}

\subsection{What is Continuing Professional Development (CPD)?}

Continuing professional development (CPD) is the educational and developmental work and learning that individuals undertake as members of their chosen occupation. It can be considered as the process of constantly updating personal skills and knowledge. Continuing (or continuous) professional development has been described as "the maintenance and enhancement of the knowledge, expertise and competence of professionals throughout their careers according to a plan formulated with regard to the need of the professional, the employer, the profession and society" (Madden and Mitchell 1993, p12). While Kennie and Enemark (1998, p.162) provide another useful definition, "The systematic maintenance, improvement and broadening of knowledge and the development of personal qualities necessary for the education of professional and technical duties throughout the practitioner's life".

The underlying premise of CPD is to maintain and continue to develop one's occupational competence which is deemed vital to maintaining one's professionalism. Consequently, a person working as a professional should remain alert to new ideas, techniques and developments in their profession (Taylor, 1996). They should therefore update their skills and knowledge through a wide range of activities including but not limited to: reading, attending courses, seminars or conferences, learning and imbibing new technologies, and undertaking similar activities that would add value to existing knowledge and competences. However, Friedman and Philips (2004) highlighted the ambiguity in the definition of CPD noting as follows. "Professionals have a limited view of CPD - seeing it as training, a means of keeping up-to-date, or a way to build a career".

Increasingly, professional associations claim that CPD is: part of lifelong learning; a means of gaining career security; a means of personal development; a means of assuring the public that individual professionals are up-to-date; a method whereby professional associations can verify competence; and a way of providing employers with a competent and adaptable workforce. It would therefore be appropriate to emphasise that CPD is undertaken to maintain and enhance professional competency and the credibility of professional qualifications, with the outcomes 
being new and reinvigorated knowledge, skills and performance (Taylor, 1996; Zajkowski, Sampson and Davis, 2007). CPD is therefore a means of promoting learning, development and professionalism among practitioners, as well as a means by which the profession could be seen to be maintaining its standards.

\subsection{Why should managers be concerned with CPD?}

The above definitions infer a necessity for CPD for individuals to update professional skills and support best practice in the occupational discipline. This must be particularly important for managers, who find themselves subject to technological changes affecting, for example, information management, and therefore look to CPD as a means of adapting to this changing environment by developing new skills. This has led Hyams (1998) to feel that CPD is especially crucial for professionals in order to remain viable in the job market. This theme of job viability suggests the necessity for managers to embark on a life-long learning programme in order to avoid obsolescence of skills. Similarly, Friedman, Durkin and Phillips (2000) note that the consequences for an individual of not undertaking CPD activities are loss of professional standing and the inability to compete against other individuals in the occupational area, which will ultimately limit career advancement.

Furthermore, change is pervasive and affects the work of every manager. The world of work today is dynamic and turbulent and managers as professionals are wont to adapt to their rapidly changing work environment. In order to keep up with change managers should find CPD useful (Kennie and Enemark 1998). In fact, many professional management associations (e.g. Chartered Management Institute) recommend that their members should take part in a minimum number of hours or training units of CPD activities in order to maintain currency of membership (Fok and Ip, 2006).

The need for ongoing professional development is well-established, both from the perspective of service quality and from the viewpoint of individual career development and marketability. While the benefits of CPD for managers are clearly stated, there has been a recent trend in job advertisements to attempt to attract individuals to management positions by offering structured CPD activities or support. This represents a significant development by employers, to use CPD as an enticement to apply rather than using a record of CPD as an element of the person specification.

\subsection{CPD as a Job Benefit: The Extent of the Issue}

An observational survey of a UK jobs website, using "CPD, Manager" as a search term, produced 123 hits (accessed $8^{\text {th }}$ February 2008). However, this included managerial jobs specifying CPD as a person requirement, or a requirement for the manager to deliver CPD training to other staff. By subsequently removing the non-job benefit CPD advertisements, a total of 8 matches was derived (Table 1).

Advertisements specifying CPD as a job benefit was not limited to one specific industrial sector, but included health, engineering and construction. The advertisements ranged from a subtle "encouragement" for CPD, to a more explicit "...will participate". Yet these are written in an enticing, marketing-astute manner, to encourage applications without really committing the employer. Apart from the one advertisement stating "2 days paid CPD leave", there is typically no value attached to CPD benefit, and therefore it will be difficult for individuals to assess the true value of the benefit on offer. Moreover, there is no means of translating the CPD benefit into tangible, measurable form in the same way as a pension, or life assurance can be. In order to compare one managerial post against another, a specified budget figure would be useful (e.g. "Up to $£ 5000$ per annum to be spent on personal CPD activities"). Presumably, it is left to the individual manager to negotiate their own CPD value, which could see some losing out, or even deter some applicants.

\subsection{CPD as a job benefit?}

By referring to CPD not only gives a contemporary feel to position and organisation, it clearly demonstrates an employer's commitment to training and development of its human resources. This Guthrie (2004) feels, also highlights a clearer career progression for individuals and therefore they should be more attracted to that organisation (one of the job advertisement specifically mentioned a ready career progression - "the company provides its employees with a clear career path"). There is however, a potential danger for organisations by offering CPD as a benefit, as it might merely encourage applicants to apply, and use the training as a stepping stone onto higher positions with other employers. Nonetheless, as most employers complain about inadequate skills levels among managers (Bosworth, Davies and Wilson, 2002), by referring to CPD in this manner, the company makes a positive contribution to updating of skills of its workforce.

However, managers typically operate in a busy, pressurised work environment, which could limit their availability to undertake development activities - the benefit might therefore be lost if not taken in the year it is offered. Similarly, the individual might suffer increased pressures in order to take advantage of the CPD activities being offered - the extra stress and workload incurred cannot therefore be considered as benefits. 
Moreover, we are not informed in the job advertisements how the individual might receive the CPD benefit - will there be the usual business case and myriad of forms to complete in order to make to participate in training? What does the organisation consider to be CPD? Will the individual have to contribute themselves, either financially or in personal time? Is the benefit conditional - will training budgets be cut if the business experiences a downturn in trading? Is CPD in this context simply replacing the initial induction training that assist individuals in settling into the new job and raising their performance to normative levels? The idea that CPD is a job perk also suggests that individuals must take a long-term perspective that the development opportunities offered will enhance career prospects, and these must be sacrificed against any tangible job benefits that the individual might seek at the present (e.g. a healthcare scheme).

Jones and Robinson (1997) are critical of companies in their handling of CPD, stating issues to include, lack of coherent policy and little evidence of coordinating development activities. Perhaps more startling was that Jones and Robinson (1997) found that most organisations were unable to cost professional development activities. If this is the case for the majority of organisations, how can they know the cost in time or money of CPD activities, to be able to offer it as a benefit? Perhaps more worrying is that Wills (1998 cited in Sandelands, 1998) finds that CPD is perceived as a luxury in most companies, and is usually scrapped in adverse trading conditions.

Additionally, the reference to mandatory CPD in the observational analysis of job advertisements - "The post-holder will participate..." represents a more sinister development. Despite some support for mandatory CPD among employers (Toon, 1998), Guthrie (2004) identifies that very little CPD is actually instigated by the employer, mostly originating from the individual. In the same way Watkins (1999) warns professional associations to be wary of adopting compulsory CPD, this approach could deter potential job applicants if they perceive CPD as not a benefit but in fact an additional burden to workload.

Despite attempts by some professional bodies to link CPD to the maintenance of membership status, the interest in formal CPD schemes among professional management associations is low. By employers offering it therefore as a job benefit knowing the take-up will be similarly low, the employer will undoubtedly incur little or no cost.

Yet CPD remains irresistible for professionals. Individuals are now expected to engage in education and learning throughout their lives to maintain and progressively update skills and knowledge. For a manager working in a dynamic organisational environment, CPD becomes of paramount importance to contribute to organisational performance. Consequently, it is this increased usefulness to the business that moves CPD from being a job benefit for an individual, to something that must surely be embedded in the job itself. In particular, health professionals, and similarly, health managers need to have evidence of CPD in order to practice - it is a necessity of the job, for which employing organisations should make provision, not offer it as a benefit (or reward).

Several academic writers insist on managerial development being linked to work activities (Garavan Barnicle and O'Suilleabhain, 1999, Raelin, 1990). Moreover, CPD activities can complement workplace development schemes such as appraisals and Investors in People (IIP) awards. Here, the relationship between CPD and organisational performance is clearly apparent and must be important to businesses to enable them to cope with external change more effectively.

\section{Conclusion}

To secure employment with an organisation that takes a positive approach to CPD must be precious, since the employer is clearly reinforcing it's commitment to the career progression of its employees. Yet at the same time, it is taking advantage of increased work performance from that individual, and helping develop a learning organisation. A record of CPD activities is therefore important for individuals to provide employers with evidence of maintaining professional skills, and can support assessment against higher standards when seeking promotion. Thus CPD creates a win-win situation for both the organisation and the individual, and so rather than being a job benefit, should be an integral part of the job itself.

Moreover, CPD not only increases the usefulness of individuals to the business but also raises the professional standing of professionals by extending knowledge and skills. According to Houle (1980), CPD is a key contributor to the professionalisation of an occupation area, which is vital for non-statutory bodies to raise the profile of the profession, especially among employers. Coen (2004) argues that CPD is congruent with professionalism, since continued credibility in an occupational area is maintained through development of competences. To therefore state $\mathrm{CPD}$ as a job benefit suggests an organisation merely feeding-off the professionalism of the individual which is morally inappropriate. As a result, professionals should insist that CPD is at the very core of any job they apply for, and not merely an incentive to entice application.

Nonetheless, this article has only sought to raise fresh debate on the topic of CPD. What is now required is further empirical research into the perceptions and attitudes of those affected by CPD as a job benefit, before a definitive conclusion can be drawn. 


\section{References}

Bosworth, D., Davies, R. \& Wilson, R. (2002). Managerial Qualifications and Organisational Performance: An Analysis of ESS 1999, Research Brief RBX05-02, Nottingham, DfES Publications.

Coen, A. (2004). The Power of CPD. Accountancy, 134, pp. 114.

Farndale, E. \& Brewster, C. (2005). In search of legitimacy: personnel management associations worldwide. Human Resource Management Journal, 15(3), 33-48.

Friedman, A., Durkin, C. \& Phillips, M. (2000). CPC: what are the true costs of continuing professional development? Continuing Professional Development, 3, 78-87.

Friedman, A. \& Philips, M. (2004). Continuing professional development: developing a vision. Journal of Education and Work, 17(3), 361-376.

Fok, A. \& Ip, H. (2006). An Agent-Based Framework for Personalized Learning in Continuing Professional Development. International Journal of Distance Education Technologies, 4(3), 48-61.

Garavan T.N, Barnicle, B. \& O'Suilleabhain, F. (1999). Management development: contemporary trends, issues and strategies. Journal of European Industrial Training, 23(4/5), 191-207.

Greller, M.M. (2006). Hours invested in professional development during late career as a function of career motivation and satisfaction. Career Development International, 11(6), $544-559$.

Guthrie, L. (2004). Action reply. Financial Management, November, pp. 26-28

Houle, C. O. (1980). Continuing Learning in the Professions, San Francisco, Jossey-Bass.

Hyams, E. (1998). Professional associations and the role of CPD. Assignation, 5(3), 8-12.

Jones, N. \& Robinson, R. (1997). Do organizations manage continuing professional development? Journal of Management Development, 16(3), 197-207.

Kennie, T.J.M. \& Enemark, S. (1998). The growing importance of CPD. Continuing Professional Development, 1, 160-169.

Madden, C.A. \& Mitchell, V.A. (1993). Professions, standards and competence: a survey of continuing education for the professions. University of Bristol, Department for Continuing Education.

Raelin, J.A. (1990). Let's not teach management as if it were a profession. Business Horizons, March/April, pp. 23-28.

Rothwell, A. \& Arnold, J. (2005). How HR professionals' rate 'continuing professional development'. Human Resource Management Journal, 15(3), 18-32

Sanderlands, E. (1998). Emerging issues in Continuing Professional Development. Continuing Professional Development, 1(2), 74-84.

Taylor, N. (1996). Professionalism and monitoring CPD: Kafka revisited. Planning Practice and Research, 11(4), 379-389

Toon, J. (1998). Continuing personal and professional development: A mandatory requirement or an ethical value regarded by members as a high priority in their personal lives? Management Accounting, September, 15(6), p. 65.

Watkins, J. (1999a). UK professional associations and continuing professional development: a new direction? International Journal of Lifelong Education, 18(1), 61-75

Zajkowski, M., Sampson, V. \& Davis, D. (2007). Continuing professional development: perceptions from New Zealand and Australian Academics. Accounting Education, 16(4), 405-420. 
Table 1. Observational Findings of CPD as a Job Benefit for Managers

\begin{tabular}{ll}
\hline Job Positions - (Samples) & Quoted CPD Benefit \\
\hline Project Controller & "Flexible working environments with organisations that actively encourage CPD" \\
Ward Manager & "'We offer a comprehensive CPD programme" \\
Project Manager & "Active support for relevant CPD" \\
Case Manager & "The post-holder will participate in the monthly CPD/Training programme" \\
Value Manager & "The company provides its employees with a clear career path, with progressive \\
training and CPD initiatives" & "CPD is actively encouraged and supported" \\
Administrative Support & \\
Officer & "2 days paid study leave per year for CPD" \\
Pharmacy Manager & "Full benefits include pension, BUPA, life assurance, CPD" \\
Engineering Manager &
\end{tabular}

